\title{
Tuberculosis care: enhancing directly observed therapy in a peri-urban, low socioeconomic status neighbourhood
}

Elijah Zhengyang $\underline{\text { Cai }}^{1}$, MBBs, MRCs, Si Min $\underline{\text { Chua }^{2}}$, MBBS, MRCs, Monica $\underline{\operatorname{Tan}^{3}}$, MBBs, MMed, Paul Anantharajah Tambyah ${ }^{4}$, MBBS, MD

\begin{abstract}
Tuberculosis (TB) is a major health issue in the Philippines. TB-Care was introduced in 2011 to tackle pulmonary TB among the urban poor in Payatas, Quezon City, Philippines. We evaluated the efficacy of TB-Care in increasing treatment success and compliance rates. This retrospective case series reviewed 44 patients with pulmonary TB enrolled in TB-Care from 2013 to 2014. Diagnosis and treatment of pulmonary TB was made in accordance with World Health Organization guidelines. Treatment outcomes included cure, completed treatment, successfully treated, failed treatment and transferred to another facility. 14 (73.7\%) out of 19 patients tested were bacteriologically cured. The average $100 \%$ compliance rate was $90.8 \%$ over six months. The programme successfully treated 39 (88.6\%) patients. This was comparable to the overall national treatment success rate of $90 \%$ for Philippines and $79 \%$ for Singapore, with higher compliance rates than were previously reported in this community.
\end{abstract}

Keywords: compliance, outcomes, treatment, tuberculosis, Philippines

\section{THE PROJECT}

Tuberculosis (TB) is a major health issue in the Philippines. In 2010 , it was the sixth leading cause of death, accounting for $5.1 \%$ of total deaths in the country. ${ }^{(1)}$ The prevalence of TB among the urban poor in the Metro Manila area is twice that of the prevalence among the general population. ${ }^{(1)} \mathrm{A}$ significant population of the urban poor live in Payatas, Quezon City, the Philippines, where one of the largest waste disposal facilities in Manila is located.

The TB-Care programme was introduced in 2011 by a group of medical students from Yong Loo Lin School of Medicine, National University of Singapore, Singapore. It was organised in partnership with Acts29, a non-governmental organisation, to tackle the challenges of treating TB among the urban poor in the Philippines. TB-Care aims to provide services that complement the National Tuberculosis Control Programme (NTP) in the Philippines. The NTP provides services and guidelines for the diagnosis and treatment of TB, with directly observed therapy (DOT) as its primary strategy. The programme targets a case detection rate of $85 \%$, cure rate of $85 \%$ and treatment success rate of $90 \% .^{(2)}$

We evaluated the efficacy of TB-Care in increasing treatment success and medication compliance rates among patients with pulmonary TB in Payatas, Quezon City, Philippines. This retrospective case series reviewed all patients with pulmonary TB enrolled in TB-Care from 2013 to 2014. Patients were screened via administration of a questionnaire for TB symptoms (Box 1). Diagnosis of pulmonary TB was made in accordance with the World Health Organization (WHO) case definition guidelines, ${ }^{(3)}$ via either bacteriological or clinical diagnosis. The treatment of new and relapsed cases of TB involved six and eight

\section{Box 1. Symptoms/signs in tuberculosis (TB) screening questionnaire:}

Children 0-9 yr (suspect symptomatic TB and refer to health centre if $\geq 3$ symptoms)

- Unexplained cough or wheezing for $\geq 2$ wk

- Unexplained fever for $\geq 2 \mathrm{wk}$

- Loss of appetite or weight loss/failure to gain weight

- Failure to respond to $2 \mathrm{wk}$ of antibiotics for lung infection

- Failure to regain previous state of health $2 \mathrm{wk}$ after a viral infection/rash

- Fatigue/less playful/lethargic

Adults

- Suspect symptomatic TB if cough $\geq 2 \mathrm{wk}$

months of DOT, respectively, in accordance with then-current WHO guidelines for settings where susceptibility testing was not available. Treatment outcomes included: cure, completed treatment, successfully treated, failed treatment and transferred to another facility. ${ }^{(3)}$

Two locals from Payatas were employed as DOT officers for the TB-Care programme. Both worked as waste pickers previously and were pulmonary TB patients who had been successfully treated with DOT. Once diagnosed with pulmonary TB, patients would undergo a counselling session with the DOT officers, and were given pamphlets and educated on TB and treatment. Patients were started on a treatment regimen prescribed by the clinician. Medications were administered in front of the DOT officers. When a patient missed two doses of medications or an appointment, the DOT officers would conduct a house visit to investigate the reason for non-compliance and counsel the

${ }^{1}$ Division of Plastic, Reconstructive and Aesthetic Surgery, Department of Surgery, National University Health System, ${ }^{2}$ Army Medical Services, Singapore Armed Forces, ${ }^{3}$ Department of Anaesthesia, SingHealth, ${ }^{4}$ Division of Infectious Diseases, University Medicine Cluster, National University Health System, Singapore

Correspondence: Dr Elijah Cai, Resident, Division of Plastic, Reconstructive and Aesthetic Surgery, National University Hospital, 5 Lower Kent Ridge Rd, Singapore 119074. elijah_cai@nuhs.edu.sg 


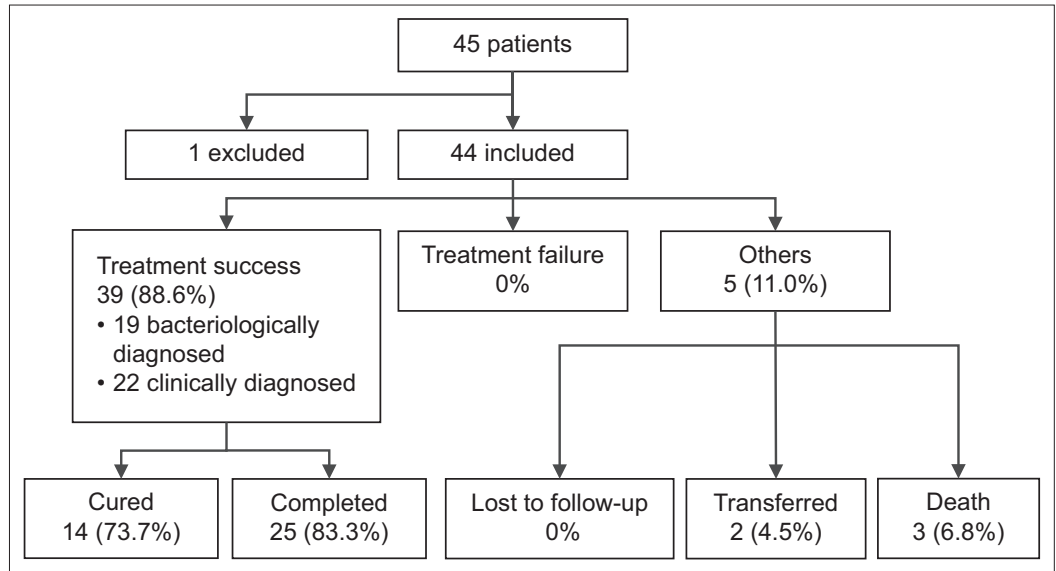

Fig. 1 Flowchart shows treatment outcomes for the patients.

\begin{tabular}{|lc|}
\hline Box 2. Cost breakdown for each patient over six months: \\
Transport to chest radiography facility & USD 4.18 \\
Chest radiography & USD 2.92 \\
Food incentive & USD 2.51 \\
Rice incentive & USD 22.55 \\
DOT officers' salary & USD 111.39 \\
Total cost & USD 143.50 \\
\hline
\end{tabular}

patients on the importance of compliance. Patients were required to attend weekly lectures. During follow-up appointments, food (e.g. biscuits and rice) was distributed to the patients as an incentive to compensate for their loss of income from time off work. Costs of consultation, investigations and transport were borne by the TB-Care programme (Box 2). Patients with a DOT monthly compliance rate of $100 \%$ would each receive $4 \mathrm{~kg}$ of rice as an incentive at the end of the month. Monthly interviews were also conducted by the DOT officers to determine barriers to care.

\section{OUTCOMES}

A total of 45 patients were enrolled from 2013 to 2014. One patient was excluded from the study as a large proportion of data was missing from his medical records. Among the 44 remaining patients, $40(90.9 \%)$ patients were newly diagnosed and $4(9.1 \%)$ were relapse cases. Owing to the limited resources available, we did not have data on comorbidities such as human immunodeficiency virus infection or diabetes mellitus. There were also no resources for TB drug susceptibility testing. There were $42(95.5 \%)$ adults and $2(4.5 \%)$ paediatric patients. $32(72.7 \%)$ of the patients were male and $12(27.3 \%)$ female, giving a maleto-female ratio of 2.7:1. $14(73.7 \%)$ out of 19 patients tested were bacteriologically cured. Excluding those who were cured, $25(83.3 \%)$ of the 30 remaining patients completed treatment, with an overall treatment success rate of $88.6 \%$. None failed treatment, while 2 ( $4.5 \%$ ) out of 44 patients transferred to another facility; 3 (6.8\%) out of 44 patients died (Fig. 1). The average $100 \%$ compliance rate was $90.8 \%$ over six months (Fig. 2).

$88.6 \%$ of our study population were successfully treated for TB. This is comparable to the overall national treatment success rate in 2013 of $90 \%$ for Philippines and $77 \%$ for Singapore. ${ }^{(4)}$ It should be noted that the $90 \%$ stated in the NTP surveillance

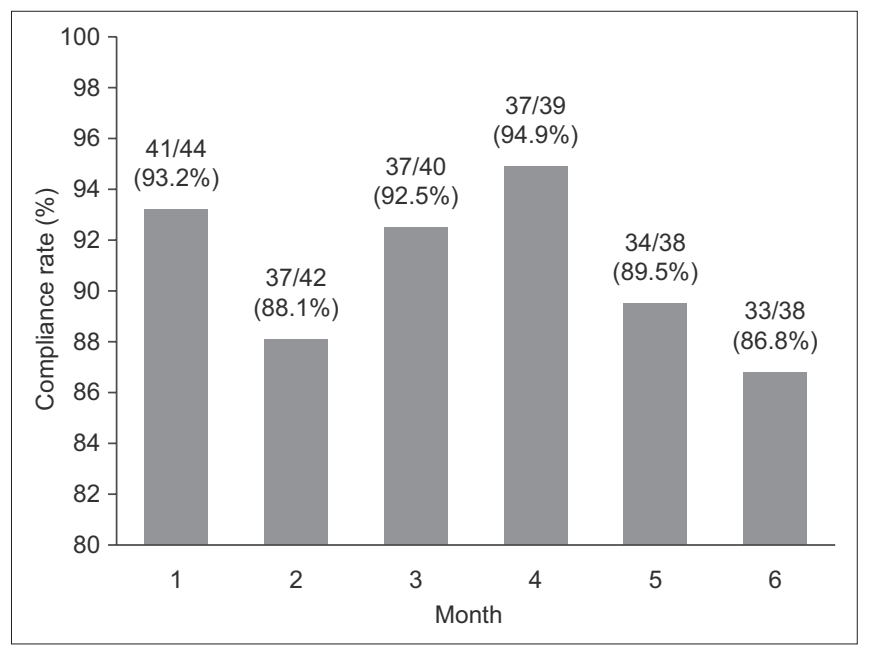

Fig. 2 Graph shows the compliance rates of patients in TB-Care programme.

report reflects the status of the whole country and does not take into account differences in the poorer regions. Within Quezon City, the cure rate is $67.4 \%-71.9 \%,{ }^{(5)}$ which is comparable to the $73.7 \%$ cure rate for the present study. In our study, the average compliance rate was $90.8 \%$ over six months. This exceeds the compliance rate of $70 \%-72 \%$ in Quezon City. ${ }^{(5)}$ In comparison to other independent TB DOT programmes in rural communities, our treatment success rate of $88.6 \%$ was comparable to those in Nigeria, ${ }^{(6)}$ Thailand $^{(7)}$ and Tanzania, ${ }^{(8)}$ which were $85.45 \%, 75.5 \%$ and $66.5 \%$, and even to developed countries such as Singapore ${ }^{(9)}$ with a success rate of $79 \%$. $^{(4)}$

The NTP has been successful in making DOT accessible to the general population, achieving treatment success rates of $90 \%{ }^{(4)}$ However, due to poverty, the people in Payatas face unique challenges that affect compliance, including hidden costs such as income lost during follow-up appointments when patients are not able to work. Additionally, NTP does not cover the cost of the chest radiography. TB-Care may be able to minimise these challenges, as it provides financial aid for chest radiography and transportation. Food given out during follow-up appointments would make up for the loss of income from time off work. The monthly rice incentive, in addition to providing motivation for compliance, provides nutritional supplementation for the patients. 
These initiatives were developed after extensive consultation with the local non-governmental organisation and locals in the community. Patient performance-based incentive schemes have been shown to work in both developed and developing countries.(10) In Singapore, a 'DOT and Shop' scheme demonstrated that providing grocery vouchers to lowincome patients as an incentive improved treatment completion rates. ${ }^{(1)}$ Our DOT officers, being previous TB patients who had experienced DOT themselves, had more credibility and rapport among the community.

\section{CONCLUSION}

Implementing DOT in an urban poor community is challenging. TB-Care achieved a treatment success rate of $88.6 \%$, which is comparable to national treatment programmes in other Southeast Asian countries. TB-Care achieved a significantly higher compliance rate than in previous reports. ${ }^{(4)}$ This pilot programme by Singaporeans in partnership with Filipinos shows promising results using simple and cost-effective methods and patient empowerment. It addresses hidden costs and provides socioemotional support to patients and could be considered in other low-resource settings.

\section{REFERENCES}

1. National Tuberculosis Control Program, Department of Health, the Philippines. Manual of procedures. 5th ed. Available at: https://www.doh.gov.ph/sites/
default/files/publications/MOP_Final_a.pdf. Accessed June 21, 2015.

2. Department of Health, Government of the Philippines; Philippine Coalition against Tuberculosis. Comprehensive and unified policy for TB control in the Philippines. Available at: http://www.philhealth.gov.ph/partners/providers/pdf/ ComprehensiveUnifiedPolicy_TB.pdf. Accessed October 1, 2015.

3. World Health Organization. Guidelines for treatment of tuberculosis. 4th ed. Available at: http://www.who.int/tb/publications/2010/9789241547833/en/. Accessed June 7, 2016.

4. The World Bank. Tuberculosis treatment success rate (\% of new cases). Available at: http://data.worldbank.org/indicator/SH.TBS.CURE.ZS. Accessed June 7, 2016.

5. Balanag VM Jr, Francisco NA, Naval SS, Lacson JIR, Zaldivar CA. A randomised trial comparing twice weekly clinic-based treatment and daily family supervised home treatment in new cases of pulmonary tuberculosis. Phil j Chest Dis [online]; 12:7-11. Available at: https://pdfs.semanticscholar.org/aea3/ f7e82462c69c4cb00e01b35a42a647e06b8f.pdf. Accessed June 7, 2016.

6. Sunday O, Oladimeji O, Ebenezer F, et al. Treatment outcome of tuberculosis patients registered at DOTS Centre in Ogbomoso, Southwestern Nigeria: a 4-year retrospective study. Tuberc Res Treat 2014; 2014:201705.

7. Sukrakanchana-Trikham P, Puéchal X, Rigal J, Rieder HL. 10-year assessment of treatment outcome among Cambodian refugees with sputum smear-positive tuberculosis in Khao-I-Dang, Thailand. Tuber Lung Dis 1992; 73:384-7.

8. Rutta E, Kipingili R, Lukonge $\mathrm{H}$, et al. Treatment outcome among Rwandan and Burundian refugees with sputum smear-positive tuberculosis in Ngara, Tanzania. Int J Tuberc Lung Dis 2001; 5:628-32.

9. Chee CB, Lim LK, KhinMar KW, et al. Surveillance of tuberculosis treatment outcomes of Singapore citizens and permanent residents, 2002-2011. Int J Tuberc Lung Dis 2014; 18:141-6.

10. Beith A, Eichler R, Weil D. Performance-based incentives for health: a way to improve tuberculosis detection and treatment completion? Working Paper 122. April 2007. In: Center for Global Development [online]. Available at: https://www.cgdev.org/publication/performance-based-incentives-health-wayimprove-tuberculosis-detection-and-treatment. Accessed June 7, 2016.

11. Chua AP, Lim LK, Ng H, Chee CB, Wang YT. Outcome of a grocery voucher incentive incentive scheme for low-income tuberculosis patients on directly observed therapy in Singapore. Singapore Med J 2015; 56:274-9. 